\title{
Evaluation of the association between dyslipidemia and hypertensive disorder of pregnancy: a nested case control study
}

\author{
Sarin Varghese, Dibu Sam*, Anuja Abraham, Kavitha Abraham, Preethi R. N.
}

Department of Obstetrics and Gynecology, Christian Medical College Hospital, Vellore, Tamil Nadu, India

Received: 29 February 2020

Accepted: 30 March 2020

*Correspondence:

Dr. Dibu Sam,

E-mail:dibu0987@gmail.com

Copyright: (C) the author(s), publisher and licensee Medip Academy. This is an open-access article distributed under the terms of the Creative Commons Attribution Non-Commercial License, which permits unrestricted non-commercial use, distribution, and reproduction in any medium, provided the original work is properly cited.

\begin{abstract}
Background: Hypertensive disorders of pregnancy are an elusive group of diseases with multifactorial etiopathologies and varied manifestation. Abnormal pre pregnancy lipid profile is shown to have a positive correlation with endothelial dysfunction which in turn leads to development of hypertensive disorder of pregnancy.

Methods: A total of 222 pregnant women who were aged between 18-35 years, with no obstetric and medical risk factors and less than 16 weeks of gestation who gave informed written consent were recruited for the study. Their baseline demographics and fasting blood samples were collected, blood samples were centrifuged, and serum was stored at -80-degree celsius. Patients were followed up till delivery and those with hypertensive disorders in pregnancy $(n=22)$ was identified, defined as case. Control was selected after matching for body mass index and frozen serum samples were analyzed.

Results: Overall incidence of hypertensive disorders in pregnancy in the study group was $12.4 \%$. The mean early trimester fasting lipid values were higher in patients who developed hypertensive disorders, difference in mean between cases and controls was TC - $16.25 \mathrm{mg} / \mathrm{dl}$ (p-0.061), TGL- $21.45 \mathrm{mg} / \mathrm{dl}$ (p-0.143), LDL- $2.4 \mathrm{mg} / \mathrm{dl}$ (p-0.82) and for HDL $4.55 \mathrm{mg} / \mathrm{dl}(\mathrm{p}-0.25)$. However, on stratification of early trimester fasting lipid level based on National Cholesterol Education Program (NCEP) criteria, Total cholesterol level greater than $160 \mathrm{mg} / \mathrm{dl}$ showed an odds ratio of 12.66 (p-0). Patients with early trimester fasting total cholesterol levels greater than $160 \mathrm{mg} / \mathrm{dl}$ has a higher risk of developing hypertensive disorder in pregnancy.
\end{abstract}

Keywords: Fasting lipid profile, Gestational hypertension, Hypertensive disorder in pregnancy, Pregnancy, Preeclampsia

\section{INTRODUCTION}

Hypertensive disorders in pregnancy contributes to significant maternal and perinatal morbidity and mortality especially in the setting of pre-eclampsia. ${ }^{1}$ The aetiology of hypertensive disorders and pre-eclampsia is multifactorial with various theories of genetic origin, immune maladaptation, placental ischemia- reperfusion injury leading to oxidative stress and endothelial dysfunction, imbalance of angiogenic and antiangiogenic factors being proposed. ${ }^{2}$ Despite the various postulates, the onset of hypertension in pregnancy and pre-eclampsia continues to be unpredictable due to its complex pathophysiology, several biochemical and biophysical markers for the prediction of hypertensive disorders have been studied. ${ }^{3}$ However, no method has been recommended as a method for screening.

There have been multiple studies looking at the association of lipids and hypertensive disorders. This is based on the premise that accumulation of lipids in the endothelial cells leads to endothelial dysfunction by way of pro-inflammatory response and oxidative stress. Pregnancy is a state of hyperlipidaemia and have shown 
levels of triglycerides to be significantly higher in those developing hypertensive disorders. Several studies correlating lipid levels with hypertensive disorders have been done but most of them describe the measurement of serum lipid levels after a diagnosis of hypertension was made. A few prospective studies have shown that women with high triglycerides are destined to develop preeclampsia., ${ }^{4,5}$ Clausen et al however found hypertriglyceridemia to be associated with early onset pre-eclampsia and not pre-eclampsia of late onset. ${ }^{6}$ Metaanalysis by Gallos et al reviewed 24 case control studies (2720 women) and 5 cohort studies that recruited 3147 women in second trimester and concluded that preeclampsia was associated with higher levels of serum triglycerides. ${ }^{?}$

Hypertensive disorders in pregnancy are thought to arise as a result of failure of the second wave of trophoblastic invasion into the spiral arterioles thus inhibiting conversion of the utero-placental unit into a high flow, low resistance unit. The second wave of invasion takes place at around 16-18 weeks. Collecting blood samples for lipid analysis prior to 16 weeks would help identify if high levels of lipids prior to 16 weeks which would contribute to the alteration of blood flow in the uteroplacental unit as a result of lipid accumulation in the endothelial cells of the arterioles.

This study collected blood samples before sixteen weeks of gestational age and followed up patients till delivery. Ours is a prospective nested case control study to analyse the association between dyslipidaemia in early pregnancy with development of hypertensive disorders during pregnancy.

\section{METHODS}

The study was conducted at the outpatient department of the obstetrics units in the Christian Medical College Hospital, Vellore, a tertiary care teaching hospital in South India. Approval from the institutional review board (10851/observe/04.09.2017) was obtained and study was conducted from September 2017 to November 2018.

The study participants included all pregnant women aged between 18-35 years presenting to the outpatient department with a singleton pregnancy, gestational age less than 16 weeks, planning on delivery in our hospital and willing for written informed consent. Women with chronic hypertension or systemic diseases that predispose to hypertension like renal disease, collagen vascular disease, pre-gestational diabetes, thrombophilia's of pregnancy or APLA syndrome were excluded from the study.

Gestational age was confirmed by a first trimester ultrasound. Blood pressure were measured by Heines manual sphygmomanometer. Detailed medical and obstetric history was obtained, and baseline demographics were collected.
All those fulfilling the study criteria and consenting, had their blood samples collected for fasting lipid profile before 16 weeks of gestational age. These samples were centrifuged, and serum stored in the Biochemistry Laboratory at $-80^{\circ}$ Celsius. The patients were then followed up till delivery. From this cohort of patients, any woman who developed hypertensive disorder of pregnancy according to ACOG 2013 criteria was defined as a case. Cases were matched for BMI among those who remained normotensive till delivery and controls were selected. After identification of the cases and controls, samples that were stored were analyzed for fasting lipid values.

\section{Sample size}

A difference in proportion of $40 \%$ between hypertensive and normotensive was chosen, as triglycerides were found to be $40-50 \%$ higher in pre-eclampsia as compared to normal pregnancies in prior studies. ${ }^{8,9}$ Twenty cases were required to obtain a difference of $40 \%$ between the proportion of dyslipidemia among subjects with and without hypertensive disorders in pregnancy, with $80 \%$ power and 5\% significance. Analysis of monthly audits conducted in our institution showed the incidence of hypertensive disorders in pregnancy to be in the range of $10-12 \%$, hence the number of subjects to be recruited was calculated as $220(11 \%)$, to obtain 20 cases with hypertensive disorder.

\section{RESULTS}

A total of 222 women were recruited into the study aged 19 to 35 years, amongst these $39(17.5 \%)$ were lost to follow-up and $6(2.7 \%)$ had second trimester pregnancy loss. One hundred and seventy-seven women were followed up till delivery, of which 92.1 percent (n 165) delivered at term and 7.9 percent (n 14) were preterm deliveries. Twenty-two women (12.4\%) developed hypertensive disorders in pregnancy (defined as cases) of which $16(72.2 \%)$ had gestational hypertension (GHTN) and 6 cases $(27.2 \%)$ were of pre-eclampsia with severe features (PE). One sample each from GHTN and PE were noted to be lysed, hence were excluded.

\section{Table 1: Baseline characteristics of the} study participants.

\begin{tabular}{|lll|}
\hline Baseline & Cases & Controls \\
\hline Age (years) & $28 \pm 3.2$ & $24.65 \pm 3.7$ \\
\hline BMI $\left(\mathrm{Kg} / \mathrm{m}^{2}\right)$ & $24.80 \pm 4.1$ & $24.80 \pm 4.0$ \\
\hline Primi gravida & 12 & 10 \\
\hline Multi gravida & 8 & 10 \\
\hline GA @ delivery (weeks) & 38.10 & 38.05 \\
\hline Birth weight $(\mathrm{Kg})$ & $3.07 \pm 0.5$ & $2.89 \pm 0.4$ \\
\hline
\end{tabular}

The baseline characteristics of both cases and controls were comparable with no significant difference in either parity or gestational age at delivery although a small 
difference was noted in age (Table 1). The mean fasting lipid levels were higher in women who developed hypertensive disorders in pregnancy, but they were not statistically significant. The mean total cholesterol level was $185.85 \mathrm{mg} / \mathrm{dl}$ amongst those who developed hypertension in pregnancy and was $169.6 \mathrm{mg} / \mathrm{dl}$ among those who remained normotensive throughout pregnancy
(Table 2). The mean lipid profile values were higher in those who developed hypertensive disorders in pregnancy. However, when the total cholesterol levels were stratified and analysed as lesser and greater than $160 \mathrm{mg} / \mathrm{dl}$ a significant difference was found in the total cholesterol levels with an odds ratio of 12.6 (Table 3 ).

Table 2: Maternal mean lipid concentration according to cases (hypertensives) and control (normotensives).

\begin{tabular}{|llllll|}
\hline Lipid levels $(\mathrm{mg} / \mathrm{dl})$ & Cases & Controls & $\begin{array}{l}\text { Difference } \\
\text { in mean }\end{array}$ & OR $(\mathbf{9 5 \%}$ CI) & p value \\
\hline Total cholesterol (TC) & $185.85 \pm 26.91$ & $169.6 \pm 24.12$ & 16.25 & $1.027(0.999,1.055)$ & 0.061 \\
\hline Triglycerides (TG) & $165.35 \pm 54.04$ & $141.9 \pm 43.18$ & 21.45 & $1.010(0.996,1.025)$ & 0.143 \\
\hline Low density lipoprotein (LDL) & $115.05 \pm 40.27$ & $112.65 \pm 29.47$ & 2.4 & $1.002(0.984,1.020)$ & 0.826 \\
\hline High density lipoprotein (HDL) & $44.95 \pm 13.64$ & $40.4 \pm 10.74$ & 4.55 & $1.033(0.977,1.092)$ & 0.25 \\
\hline
\end{tabular}

Table 3: Maternal lipid concentration according to cases (hypertensives) and controls (normotensives) stratified according to NLCP criteria.

\begin{tabular}{|c|c|c|c|c|}
\hline Lipid levels (mg/dl) & Cases (number) & Controls (number) & OR & p value \\
\hline Total cholesterol $\leq 160$ & 1 & 8 & \multirow{2}{*}{12.66} & 0.020 \\
\hline Total cholesterol >160 & $19(95 \%)$ & $12(60 \%)$ & & \\
\hline Triglycerides $\leq 150$ & 7 & 11 & \multirow{2}{*}{2.27} & 0.204 \\
\hline Triglycerides $>150$ & $13(65 \%)$ & $9(45 \%)$ & & \\
\hline LDL $\leq 130$ & 15 & 13 & \multirow{2}{*}{0.61} & 0.490 \\
\hline LDL $>130$ & $5(25 \%)$ & $7(35 \%)$ & & \\
\hline $\mathrm{HDL} \leq 50$ & 14 & 17 & \multirow{2}{*}{0.41} & 0.451 \\
\hline $\mathrm{HDL}>50$ & $6(30 \%)$ & $3(15 \%)$ & & \\
\hline
\end{tabular}

Table 4: Comparison of maternal mean lipid concentration between patients with gestational hypertension and pre-eclampsia.

\begin{tabular}{|lllll|}
\hline $\begin{array}{l}\text { Lipid levels } \\
(\mathbf{m g} / \mathbf{d l})\end{array}$ & $\begin{array}{l}\text { Pre-eclampsia } \\
\text { mean } \pm \text { SD }\end{array}$ & $\begin{array}{l}\text { Gestation } \\
\text { hypertension }\end{array}$ & $\begin{array}{l}\mathbf{9 5 \%} \text { confidence interval } \\
\text { of the difference }\end{array}$ & p value \\
\hline Total cholesterol & $178.60 \pm 40.87$ & $188.27 \pm 21.92$ & $-39.281-19.948$ & 0.502 \\
\hline Triglycerides & $147.20 \pm 60.14$ & $171.40 \pm 52.65$ & $-83.23-34.83$ & 0.400 \\
\hline HDL & $49.80 \pm 9.39$ & $43.33 \pm 14.69$ & $-8.392-34.831$ & 0.373 \\
\hline LDL & $108.400 \pm 36.108$ & $110.67 \pm 44.698$ & $-48.85-44.31$ & 0.920 \\
\hline
\end{tabular}

All patients who developed gestational hypertension and $80 \%$ of those who developed pre-eclampsia had cholesterol levels greater than $160 \mathrm{mg} / \mathrm{dl}$. Comparison of total cholesterol levels between gestational hypertension and pre-eclampsia showed no significant difference. Study also found no difference in the level of triglycerides, LDL cholesterol or HDL cholesterol between the two groups, nor was there any difference in those who developed pre-eclampsia (Table 4).

\section{DISCUSSION}

The prevalence of hypertensive disorders in pregnancy in our cohort was $11 \%$, which is similar to the prevalence recorded worldwide of $8-10 \% .{ }^{10}$ Of the women who developed hypertensive disorder $2.8 \%$ had features of pre-eclampsia with severe features which is lesser than the global rates of $4-8 \%$. The monthly institutional audits in the department record the hypertensive disorders to be in the range of $11-12 \%$, of which the pre-eclampsia rates are around $4-5 \%$.

The lower rates of pre-eclampsia in this cohort can be explained by the fact that most of the patients with preeclampsia are referred to us in the late second or early third trimester and their samples for lipid profile were unavailable due to the study design. The present study however failed to show a hypertriglyceridemia dyslipidemia pattern in those who developed hypertension or pre-eclampsia. This contrasts with findings in studies done by Lorentzen and Clausen et al. ${ }^{6,9}$ 
In this study, we found total cholesterol levels of greater than $160 \mathrm{mg} / \mathrm{dl}$ to be elevated in hypertensive pregnant women in comparison with those who remained normotensive and this was similar to studies done by Enquobahrie and van den Elzen et al. ${ }^{5,11}$

First trimester hypercholesterolemia correlates significantly with the risk of developing hypertensive disorders in the latter part of pregnancy. However, the levels did not correlate with the severity of hypertensive disorders as no difference was noted in the level of hypercholesterolemia when gestational hypertension was compared with preeclampsia.

\section{ACKNOWLEDGMENTS}

Authors would like to thank Professor Annie Reji, MD, department of obstetrics and gynecology, Christian Medical College Hospital, Vellore, Tamil Nadu, India for her constant and kind support and Rekha Karuppusami Lecturer, Msc biostatistics, department of biostatistics, Christian Medical College Hospital, Vellore, Tamil $\mathrm{Nadu}$, India for her assistance in the statistical analysis.

Funding: No funding sources Conflict of interest: None declared

Ethical approval: The study was approved by the Institutional Ethics Committee

\section{REFERENCES}

1. Say L, Chou D, Gemmill A, Tunçalp Ö, Moller AB, Daniels J, Gülmezoglu AM, Temmerman M, Alkema L. Global causes of maternal death: a WHO systematic analysis. Lancet Glob Health. 2014;2(6):e323-333.

2. Lambert G, Brichant JF, Hartstein G, Bonhomme V, Dewandre PY. Preeclampsia: an update. Acta Anaesthesiol Belg. 2014;65(4):137-49.

3. Monte S. Biochemical markers for prediction of preclampsia: review of the literature. J Prenat Med. 2011;5(3):69-77.
4. Lorentzen B, Endresen MJ, Clausen T, Henriksen T. Fasting serum free fatty acids and triglycerides are increased before 20 weeks of gestation in women who later develop preeclampsia. Hypertens Preg. 1994;13(1):103-9.

5. Enquobahrie DA, Williams MA, Butler CL, Frederick IO, Miller RS, Luthy DA. Maternal plasma lipid concentrations in early pregnancy and risk of preeclampsia. Am J Hypertens. 2004;17(7):574-81.

6. Clausen T, Djurovic S, Henriksen T. Dyslipidemia in early second trimester is mainly a feature of women with early onset pre-eclampsia. BJOG Int J Obstet Gynaecol. 2001;108(10):1081-7.

7. Gallos ID, Sivakumar K, Kilby MD, Coomarasamy A, Thangaratinam S, Vatish M. Pre-eclampsia is associated with, and preceded by, hypertriglyceridaemia: a meta-analysis. BJOG Int $\mathbf{J}$ Obstet Gynaecol. 2013;120(11):1321-32.

8. Potter JM, Nestel PJ. The hyperlipidemia of pregnancy in normal and complicated pregnancies. Am J Obstet Gynecol. 1979;133(2):165-70.

9. Lorentzen B, Endresen MJ, Hovig T, Haug E, Henriksen T. Sera from preeclamptic women increase the content of triglycerides and reduce the release of prostacyclin in cultured endothelial cells. Thromb Res. 1991;63(3):363-72.

10. Duley L. The global impact of pre-eclampsia and eclampsia. Semin Perinatol. 2009;33(3):130-7.

11. van den Elzen HJ, Wladimiroff JW, Cohen-Overbeek TE, de Bruijn AJ, Grobbee DE. Serum lipids in early pregnancy and risk of pre-eclampsia. $\mathrm{Br} \mathrm{J}$ Obstet Gynaecol. 1996;103(2):117-22.

Cite this article as: Varghese $S$, Sam D, Abraham A, Abraham K, Preethi RN. Evaluation of the association between dyslipidemia and hypertensive disorder of pregnancy: a nested case control study. Int J Reprod Contracept Obstet Gynecol 2020;9:2073-6. 